\title{
Prevalence of husband antenatal care attendance and associated factors among husbands whose wives gave birth in the last twelve months in Enebsiesarmider District, Northwest Ethiopia, 2018.
}

Haimanot Abebe Adane ( $\sim$ haimanotabebe78@gmail.com )

Wolkite University

Haimanot Abebe

Wolkite University

Lemma Getacher

Debre Berhan University

Samuel Derbie

Debre Markos University

Research article

Keywords: Antenatal care, Ethiopia, Male involvement

Posted Date: September 11th, 2019

DOI: https://doi.org/10.21203/rs.2.14295/v1

License: (c) (1) This work is licensed under a Creative Commons Attribution 4.0 International License.

Read Full License 


\section{Abstract}

Background Globally, husband attendance of skilled maternal ANC care remains a challenge to safe motherhood. Even though husband attendance in antenatal care is one of the strategies for enhancing reproductive and sexual health in Ethiopia, the magnitude of husband attendance in ANC is not well investigated in the study area. Therefore, this study aimed to assess husband antenatal care attendance and associated factors among husbands whose wives gave birth in the last twelve months prior to the study in Enebsiesarmider district, Northwest Ethiopia.

Methods A Community-based cross-sectional study was employed to assess husband antenatal care attendance and associated factors among husbands whose wives gave birth in the last twelve months in Enebsiesarmider district, Northwest Ethiopia. The study was conducted from February 10-March 10, 2018. A total of 402 participants were involved in the study. Multi stage sampling method was used to recruit study participants. Data were collected using structured interviewer administered questionnaire. Data were entered using epi Data software and exported to SPPS for analysis. Descriptive statistics including mean, proportion were used to describe study variables. Binary and multivariable logistic regression was employed to describe variables in relation to the outcome variable.

Result: The prevalence of husband antenatal care attendance was found to be $31.8 \%$ [95\% Cl, 27.4-36.3]. Attending secondary education and above [AOR 1.93,95\% Cl, 1.14-3.26], good antenatal care knowledge [AOR 3.30, 95\% Cl, 2.02-5.39] and hadn't health system barriers [AOR 2.32, 95\% $\mathrm{Cl}, 1.35-4.00]$ were statistically associated with husband antenatal care attendance.

Conclusion Husband ANC attendance was found to be low in the study area. Regional health department shall design behavioral change interventions to reducing health system pitfalls towards ANC in the study area, furthermore, enabling all pregnant women to be booked for ANC and providing invitation letter to their husbands in the subsequent ANC visits seems essential to initiate husband ANC attendance.

\section{Introduction}

Husband companion at antenatal care is rare and in many communities, it is unthinkable to find male companions accompanying a woman to the labour room during delivery[1,2]. Men and women are different in regards to their roles and responsibilities that traditional society assigns to them and their position in the family and community[3-6]. Sexual and reproductive health is often considered as women's responsibilities in most developing nation [7-9].These have great influences on health care seeking practice including maternal health care utilization.

Globally, the involvement of husband in maternal health programs has been associated with positive reproductive health outcomes, such as in the use of contraceptives, birth spacing, maternal workload during pregnancy, birth preparedness, postnatal care attendance, couple communication and emotional support for women during pregnancy and improved maternal health outcomes [10-11]. In Pacific policymakers and practitioners reported that greater men's involvement would result in a range of benefits 
for maternal and child health, primarily through greater access to services and interventions for women and children[13]. Husband attendance in maternal health service utilization is promoted as a promising strategy to improve maternal and child health [14]. This is because men can also play a crucial role in supporting pregnant women, by assisting them to get to clinics or hospitals where chances of safe delivery are higher $[10,11]$. In spite of this, pregnancy and child birth continue to be regarded as exclusively women's affairs in most African countries [15-16].only few husbands participate in maternal health services including antenatal care.

A number of studies in the world have explored husband attendance in maternal health programs. For instance a study which was conducted in Nepal is 39\% [14]. In sub-Saharan Africa, husband antenatal care attendance varies between 12.5\%-18.7\% [17] and in Ethiopia studies showed that husband antenatal care attendance is rage from $19.722 .7 \%$ [18-20]. Husband ANC attendance program still remains low in developing countries including Ethiopia [11-13]. Recent studies on the topic suggest that there were a number of reasons for low level of husband antenatal care attendance which include cultural barriersand norms, knowledge on ANC, sociodemographic characteristics, male individual opinions and health system barriers[21-24]

According to the EDHS 2016 report only $62 \%$ of women have at least one antenatal care visit nationally and $67 \%$ of women have at least one antenatal care visit in Amhara region where the study area belongs [25]. The above mentioned national and regional ANC service utilization rate is low even compared to many developing countries. In Ethiopia in general and specifically in the study area there is largely patriarchal family structure. Women's lower status in the family, where decision regarding mobility and expenditure for health care are in the hands of men, may prevent them from seeking care for their own health problems[26]. Husbands are important actors in all family affairs including ANC in patriarchal family, lower level of ANC utilization would be attributable to lower involvement of husbands in antenatal care in Ethiopia in general and specifically in the study area.

Husband attendance in antenatal care is crucial to bring desirable level of service utilization among women. It is helpful for timely ANC booking and to enable them to have continued care. Despite of the aforementioned fact level of husband involvement on ANC is not well investigated in the study area. Therefore this study aimed to assess the prevalence of husband ANC attendance by accompanying his wife and associated factors in Enebsiesarmider district, Northwest Ethiopia.

\section{Methods And Materials}

\section{Study setting and design and period}

Community based cross sectional study design was conducted in Enebsiesarmider district, Northwest, Ethiopia from February 10-March 10, 2018 which is located at Amhara National Regional State, in the norther west part of Ethiopia. The district has 1 district hospital, 8 health centers and 38 health posts. AllHusbands whose wives had ANC follow up during their last pregnancy and have lived in the study area for at least six months were eligible for the study. 
The required sample size for this study was calculated by using single population proportion formula: With assumption of $95 \%$ of confidence interval, margin of error tolerated (0.05), proportion of husband antenatal care attendance 0.197 [27], non-response $10 \%$ and design effect 1.5 to accommodate for intracluster variability, the maximum sample size was 402 .

Multistage sampling technique was used. There are 37 Kebeles (smallest administrative unit in Ethiopia) in Enebsiesarmider district out of which two kebeles from urban and 10 kebeles from rural were selected by simple random sampling. Finally, systematic random sampling method was employed to select each study units.

\section{Operational Definition}

Husband antenatal care attendance:- The husband accompanying status during the recent ANC visit.

Health system barriers: - was measured using five-point Likert scale questions, Respondents were asked "did you believe antenatal clinics should be opened on weekends and evening for men to attend these clinics with their partner; respondents who respond "very disagree" will score 1, "disagree" will score 2, "undecided" will score 3 , agree will score 4 and "Strongly agree" response will earn 5 score. The same pattern of questioning and scoring was made for the rest of seven health system barriers items. According to the aforementioned statements the score for each respondent could range from 8 to 40 . Respondents who have scored greater than or equal to the median value of the items "have health systembarriers'and those who have scored less than median value of the items "have health system barriers:

ANC Knowledge: - Comprehensive knowledge of ANC was computed from summing up all relevant seven knowledge items. A correct answer for each item was scored as " 1 " and incorrect answer was scored as "0." Accordingly those respondents who scored greater than or equal to the median value of knowledge assessment questions were thought as having Good knowledge and those respondents who answered less than median value of knowledge assessment questions were thought as having Poor knowledge.

\section{Data Collection Procedure}

Data were collected using a pretested and structured interviewer administered questionnaire. The English language questionnaire was translated into Amharic language (language spoken in the study area) by Amharic language speaker who has attended Master of Arts in Amharic language and was translated back to English language by a person who attended Master of Arts in English language and comparison was made on the consistency of the two versions.

The reliability of the tool for cultural and health system items was checked using Cronbach's alpha reliability test which is 0.87 and 0.93 respectively which showed the consistency of the questionnaire. To assure the data quality, 15 grade 12 completed students and BSc nurses holders were recruited as data 
collectors and supervisor, respectively. In addition, training regarding the study objectives and data collection process was given for data collectors and supervisor. Furthermore, intensive supervision was done by supervisor and principal investigators throughout the data collection period.

\section{Data Processing and Analysis}

The data were coded, cleaned, edited and entered into Epi data version 4.2.0.0 and exported to SPSS version 25. Descriptive results were presented using tables and figures. Model fitness was checked using a Hosmer-Lemeshow goodness-of-fitness test. Crude odds ratios with their $95 \%$ confidence intervals were estimated in the bi-variable logistic regression analysis to assess the association between each independent variable and outcome variable. All variables with $\mathrm{P} \leq 0.25$ in the bivariate analysis were included in the final model of multivariate analysis in order to control all possible confounders. Adjusted odds ratio with $95 \% \mathrm{Cl}$ was estimated to identify the factors associated with husband attendance in ANC using multivariable logistic regression analysis. Level of statistical significance was declared at Pvalue $<0.05$

\section{Results}

Socio- demographic characteristics of study participants

In this study, a total of 402 study participants were involved. The mean age of study participants were 35.5 (SD \pm 6.1 years). All $402(100 \%)$ of respondents were orthodox followers by religion and Amhara by ethnicity. More than four fifth, $341(84.8 \%)$ of male partners were from the rural areas. Nearly three fifth, $235(58.5 \%)$ of the respondents were no formal education. The majority, 301(74.9\%) of the study participants were farmers by their occupation (See Table 1).

Table 1: Socio- demographic characteristics of study participants in Enebsiesarmider District, East Gojjam Zone, Ethiopia, 2018( $n=402)$. 


\begin{tabular}{lll}
\hline Variable & Frequency & Percent \\
\hline $\begin{array}{l}\text { Age (Year) } \\
\leq 25\end{array}$ & 9 & 2.2 \\
\hline $26-35$ & 209 & 52 \\
\hline $36-45$ & 132 & 37.8 \\
\hline$\geq 46$ & 32 & 8 \\
\hline Residence & & \\
\hline Urban & 61 & 15.2 \\
\hline Rural & 341 & 84.8 \\
\hline Education Status & & \\
\hline No formal education & 235 & 58.5 \\
\hline Primary education & 52 & 12.9 \\
\hline Secondary and above & 115 & 28.6 \\
\hline Occupation & & \\
\hline Farmer & 301 & 74.9 \\
\hline Private Employee & 43 & 10.7 \\
\hline Merchant & 26 & 6.5 \\
\hline Government Employee & 32 & 8.0 \\
\hline Family wealth index & & \\
\hline Poor & 115 & 28.6 \\
\hline Medium & 159 & 39.6 \\
\hline Rich & 129 & 31.8 \\
\hline
\end{tabular}

ANC Knowledge

Nearly half, 190(47.3\%) of the respondents had good knowledge.

Health system variables of study participants

Regarding, health system barriers, $253(62.9 \%)$ of the respondents had health system barriers.

Furthermore, nearly half $192(47.8 \%)$ of the respondents were disagree that antenatal clinics should be opened on weekends and evening for men to attend these clinics with their partner.

Prevalence of husband antenatal care attendance

One hundred twenty eight (31.8\%) of the respondents were found to be accompanied by their wife during their recent antenatal care visit.

Factor associated with prevalence of husband antenatal care attendance

The prevalence of husband antenatal care attendance were 1.93[AOR 1.93, 95\% Cl, 1.14-3.26] times higher in males who attended secondary and above education than those who had no formal education. 
Husbands who had good knowledge about antenatal care services were 3.30[AOR 3.30, 95\% Cl, 2.025.39] times more likely to be attended in antenatal care activities than those who had poor antenatal care knowledge. Regarding health system barrier respondents who hadn't health system barrier were 2.32[AOR $2.32,95 \% \mathrm{Cl}, 1.35-4.00]$ times more likely to be attended in antenatal care services than the counterpart. (See Table 2)

Table 2: Factors associated with husband attendance in antenatal care services among husband whose wives gave birth in the last twelve month in Enebsiesarmider District, East Gojjam Zone, Ethiopia, 2018 ( $\mathrm{n}$ = 402). (Crude and adjusted OR) 
Educational status

No formal education

Primary education

\begin{tabular}{llll}
$63(26.8)$ & $172(73.2)$ & 1.00 & 1.00 \\
\hline $12(23.1)$ & $40(76.9)$ & $0.82(0.40-$ & $0.67(0.31-1.47)$ \\
& & $1.66)$ &
\end{tabular}

Secondary education and above

2.33(1.46-

1.93(1.14-3.26)*

\section{Residences}

Rural

\begin{tabular}{lll}
$103(30.2)$ & $238(69.8)$ & 1.00 \\
\hline $25(41.0)$ & $36(59.0)$ & $1.60(0.92-$ \\
& & $2.81)$
\end{tabular}

\section{Occupation}

Farmer

$\begin{array}{llll}89(29.6) & 212(70.4) & 1.00 & 1.00 \\ 13(30.2) & 30(69.8) & 1.03(0.51- & 0.81(0.34-1.93) \\ & & 2.07) & \end{array}$

Merchant

$5(19.2) \quad 21(80.8)$

0.57(0.21-

0.93(0.21-4.08)

Private Employee 1.55)

Government Employee

$\begin{array}{lll}21(65.6) & 11(34.4) & 4.55(2.11- \\ & & 9.83)\end{array}$

\section{Household wealth index}

Poor

Medium

Rich

\section{ANC knowledge}

Poor

Good

\section{Cultural Barriers}

Yes

No

$\begin{array}{ll}63(28.3) & 160(71.7) \\ 65(36.3) & 114(63.7)\end{array}$

29(25.2)

53(33.3) 106(66.7)

46(35.9) $\quad 82(64.1)$
1.00

1.47(0.87-

2.53)

$1.64(9.96-$
$2.90)$

1.00

1.27(0.47-3.47) 


\section{Wife place of delivery}

\begin{tabular}{lllll} 
Home & $56(28.7)$ & $139(71.3)$ & 1.00 & 1.00 \\
Institution & $72(34.8)$ & $135(165.2)$ & $1.32(0.87-$ & $1.48(0.93-2.37)$ \\
& & & $2.02)$ & \\
\hline
\end{tabular}

\section{Significant at $* \mathrm{P}=0.002, * * \mathrm{P} \leq 0.001, * * * \mathrm{P}=0.002$ and $1.00=$ constant.}

\section{Discussion}

The overall prevalence of husband antenatal care attendance was found to be $31.8 \%[95 \% \mathrm{Cl}, 27.4-36.3]$. This report revealed that many problem which could be resolved during antenatal care service is prevalent including allocation of money, transport and time for women to attend a health center for antenatal care, workload during pregnancy and health care children in the study area because there is highly patrilineal inheritance in the community. This is evidenced by high maternal and child morbidity and mortality in Amhara regional state in which the study area is found. This finding is in line with study report from Tigray region, Ethiopian and Central Ghana $[28,29]$. This might be now a day's almost all African countries have implemented same strategies that can increase the engagement of husbands in maternal health services through extensive work of health extension workers and health care providers. This finding is slightly higher than findings from a study conducted in Easter Ethiopia and Goba Town, Oromia region Ethiopia $[19,28]$. The difference could probably explained by the time gap as better attention has been given to husband attendance in maternal health care services these days and improvements in the health care systems.

But this finding is lower compared to the finding from Nepal, Thailand, Kenya and Ambo Town Ethiopia $[14,31-32]$. The discrepancy of these findings might be the difference in method used, sociodemographic characteristics of the study participants, and availability and accessibility of the infrastructures.

Husbands who had attended secondary and above education were 1.93 times more likely to accompany their wives in ANC than those who had no formal education. Similar studies in Nepal, Central Ghana and Goba town Ethiopia have found that education level is an important factor for husband antenatal care attendance $[14,18,29]$. This may be related to as people more educated they could easily understood the importance of husband attendance in maternal health care service including antenatal care. Moreover, educated males will have better awareness about the benefits of antenatal care service utilization.

Husbands who had good knowledge on antenatal care services were 3.30 times more likely to accompany their wives in antenatal care service than those who had poor antenatal care knowledge. This finding is similar with the studies conducted in Northern Ghana, Kenya, and Arbaminch Ethiopia [32-34]. The possible explanation for this might be having good knowledge about ANC will help the partners to know the benefit of antenatal care programme for themselves as well as their new born. On the other 
hand, husbands with poor knowledge on ANC could not have complete picture on the essence of ANC to the mother and the fetus'

Respondents who hadn't health systembarriers were 2.32 times more likely to accompany their wives in ANC services compared to their counterparts. This finding is consistent with the study findings from Uganda and Eastern Ethiopia [28, 35]. The possible justification could be those husbands who hadn't health system barriers will have the initiative to accompany their wife to health facility for antenatal care service.

\section{Conclusion}

Prevalence of husband antenatal care attendance was found to be low in the study area. Despite, the Ethiopian government adopts policies which were formulated in Cairo, Egypt on issues engaging husbands in sexual and reproductive health. The federal ministry of health in Ethiopia has not been formulated policies and strategies that could lead husbands in the attendance of antenatal care health services. Regional health department in collaboration with the district health office shall design behavioral change interventions to reducing health system pitfalls towards ANC in the study area. Furthermore, the district health care provider should give proper dissemination of knowledge about maternal health care among husbands and making the husband's presence obligatory during antenatal care visits will help primary health care units secure better husband attendance in ANC.

\section{Limitations}

Measuring the temporal relationship was not easy, as both exposure and outcome variables were collected simultaneously and the study might be subjected to recall bias because males failed to remember what they did for their wives during her antenatal follow up, but this was minimized by probing the respondents about the event.

\section{List Of Abbreviations}

ANC Antenatal Care

NGONon-Governmental Organization

SPSS Statistical package for social science

UNAIDS United Nations Programme on Human immune deficiency virus

\section{Declarations}

Ethics approval and consent to participate 
Ethical approval was obtained from Haramaya University, College of Health and Medical Sciences, Institutional Health Research Ethics Review Committee (IHRERC). All participants enrolled in the study were informed about the study objectives, expected outcomes, benefits and their right to refuse. Written consent was taken from the participants before the interview.

\section{Availability of data and materials}

Full data set and other materials pertaining to this study can be obtained from corresponding author on reasonable request.

\section{Funding}

Not Applicable.

\section{Acknowledgment}

My appreciation gone to my data collectors, supervisors, and questionnaire translators in to the local languages and study participants; without them the research would not be done.

\section{Consent for publication}

Not applicable

\section{Competing interest}

The author declares that there is no competing interest.

\section{Authors' contribution}

HA: Conceives in all research proposal development, supervised data collection process, conduct the analysis and wrote the manuscript.

\section{References}

1.Maluka SO, Peneza AK: Perceptions on male involvement in pregnancy and childbirth in Masasi District, Tanzania: a qualitative study. Reproductive Health 2018, 15(1).

2.Mkandawire $\mathrm{E}$, Hendriks SL: A qualitative analysis of men's involvement in maternal and child health as a policy intervention in rural Central Malawi. BMC Pregnancy and Childbirth 2018, 18(1).

3.Development(USAID) USAfI: Male Involvement in Maternal Health Care as a Determinant of Utilization of Skilled Birth Attendants in Kenya. 2013.

4.Ganle JK, Dery I: 'What men don't know can hurt women's health': a qualitative study of the barriers to and opportunities for men's involvement in maternal healthcare in Ghana. Reproductive health 2015, 
12:93-93.

5.International(UNFWI) UNFW: An analysis of the un 2030 sustainable development agenda. 2017.

6.Nation(UN): U: The Millennium Development Goals Report. 2015.

7.USAIDS: Male Involvement is Key to Reproductive Health. 2014.

8.Tweheyo R, Konde-Lule J, Tumwesigye NM, Sekandi JN: Male partner attendance of skilled antenatal care in peri-urban Gulu district, Northern Uganda. BMC pregnancy and childbirth 2010, 10:53.

9.WHO: World Health Organization (WHO):HewGuideline On When To Start Antiretroviral Therapy And On Pre-Exposure Prophylaxis For Hiv http://apps.who.int/iris/bitstream/10665/208825/1/9789241549684_eng.pdf 2015.

10. World Health organization(WHO).2012. Male involvement in the prevention of mother-to-child transmission of HIV. http://www.who.int/reproductivehealth.

11.Dunlap J, Foderingham N, Bussell S, Wester CW, Audet CM, Aliyu MH: Male involvement for the prevention of mother-to-child HIV transmission: A brief review of initiatives in East, West, and Central Africa. Curr HIV/AIDS Rep 2014, 11(2):109-118.

12.Tadesse M, Boltena AT, Asamoah BO: Husbands' participation in birth preparedness and complication readiness and associated factors in Wolaita Sodo town, Southern Ethiopia. Afr J Prim Health Care Fam Med 2018, 10(1):e1-e8.

13.Forbes F, Wynter K, Wade C, Zeleke BM, Fisher J: Male partner attendance at antenatal care and adherence to antenatal care guidelines: secondary analysis of 2011 Ethiopian demographic and health survey data. BMC pregnancy and childbirth 2018, 18(1):145-145.

14.Bhatta DN: Involvement of males in antenatal care, birth preparedness, exclusive breast feeding and immunizations for children in Kathmandu, Nepal. BMC Pregnancy Childbirth 2013, 13:14.

15.(IFRC) TIFoRCaRCS: Reproductive, maternal, newborn and child health today Overview and implementation analysis. 2014.

16.Tesfaye G, Loxton D, Chojenta C, Semahegn A, Smith R: Delayed initiation of antenatal care and associated factors in Ethiopia: a systematic review and meta-analysis. Reprod Health 2017, 14(1):150.

17.Kalembo FW, Yukai D, Zgambo M, Jun Q: Male partner involvement in prevention of mother to child transmission of HIV in sub-Saharan Africa: successes, challenges and way forward. Open journal of preventive medicine 2012, 2(1):35-42.

18.Alemayehu MT, Haidar J: Male involvement in prevention of mother-to-child transmission of HIV in the context of partner testing in Goba town, Ethiopia: A facility-based cross-sectional study. South African 
medical journal = Suid-Afrikaanse tydskrif vir geneeskunde 2017, 107(10):864-870.

19.Yargawa J, Leonardi-Bee J: Male involvement and maternal health outcomes: systematic review and meta-analysis. J Epidemiol Community Health 2015, 69(6):604-612.

20.Teklesilasie W, Deressa W: Husbands' involvement in antenatal care and its association with women's utilization of skilled birth attendants in Sidama zone, Ethiopia: a prospective cohort study. BMC pregnancy and childbirth 2018, 18(1):315-315.

21.Davis J, Vyankandondera J, Luchters S, Simon D, Holmes W: Male involvement in reproductive, maternal and child health: a qualitative study of policymaker and practitioner perspectives in the Pacific. Reprod Health 2016, 13(1):81.

22.Bougangue B, Ling HK: Male involvement in maternal healthcare through Community- based Health Planning and Services: the views of the men in rural Ghana. BMC public health 2017, 17(1):693-693.

23.Mullany BC, Becker S, Hindin MJ: The impact of including husbands in antenatal health education services on maternal health practices in urban Nepal: results from a randomized controlled trial. Health Educ Res 2007, 22(2):166-176.

24.Forbes F, Wynter K, Wade C, Zeleke BM, Fisher J: Male partner attendance at antenatal care and adherence to antenatal care guidelines: secondary analysis of 2011 Ethiopian demographic and health survey data. BMC Pregnancy Childbirth 2018, 18(1):145.

25.Centeral Stastical Agency(CSA). 2016. Ethiopia Demographic and Health Survey.

26.Morfaw F, Mbuagbaw L, Thabane L, Rodrigues C, Wunderlich A-P, Nana P, Kunda J: Male involvement in prevention programs of mother to child transmission of HIV: a systematic review to identify barriers and facilitators. Systematic reviews 2013, 2(1):5.

27.Asefa F: Male Partners Involvement in Maternal ANC Care: The View of Women Attending ANC in Hararipublic Health Institutions, Eastern Ethiopia. Science Journal of Public Health 2014, 2(3):182.

28.Craymah JP, Oppong RK, Tuoyire DA: Male Involvement in Maternal Health Care at Anomabo, Central Region, Ghana. Int J Reprod Med 2017, 2017:2929013.

29.Gidey G: Assessment of Husbands' Participation on Birth Preparedness and Complication Readiness in Enderta Woreda, Tigray Region, Ethiopia, 2012. Journal of Women's Health Care 2014, 03(01).

30.Lolekha R, Kullerk N, Wolfe MI, Klumthanom K, Singhagowin T, Pattanasin S, Sombat P, Naiwatanakul T, Leartvanangkul C, Voramongkol N: Assessment of a couples HIV counseling and testing program for pregnant women and their partners in antenatal care (ANC) in 7 provinces, Thailand. BMC International Health and Human Rights 2014, 14(1). 
31.Kiptoo SJ: Male Partner Involvement In Antenatal Care Services In Mumias East And West SubCounties, Kakamega County, Kenya. IOSR Journal of Nursing and Health Science (IOSR-JNHS) 2017, 2320-1940 (4):37-46.

32.Dereje Bayissa Demissie, Gizachew Abdissa Bulto, Terfassa TG: Involvement of Male in Antenatal Care, Birth Preparedness and Complication Readinessand Associated Factors in Ambo Town, Ethiopia. Journal of Health, Medicine and Nursing 2016, 27.

33.Adadow Yidana, Shamsu-Deen Ziblim, Yamusah B: Male Partner Involvement in Birth Preparedness and Utilization of Antenatal Care Services: A study in the West Mamprusi Municipality of Northern Ghana World Journal of Public Health 2018, 3(3):69-75.

34.Marelign.T, Shikur.M: Male Partners' Involvement in the Prevention of Mother-to-Child Transmission of HIV and Associated Factors in Arba Minch Town and Arba Minch Zuria Woreda, Southern Ethiopia. Biomed Res Int 2015, 2015:763876.

35.Byamugisha R, Tumwine JK, Semiyaga N, Tylleskar T: Determinants of male involvement in the prevention of mother-to-child transmission of HIV programme in Eastern Uganda: a cross-sectional survey. Reprod Health 2010, 7:12. 